\title{
TEORES DE ACIDEZ NO CALDO DE CULTIVARES TARDIOS DE CANA-DE-AÇÚCAR
}

\author{
SILVA, Joana Diniz Rosa da ${ }^{1}$ \\ SILVA NETO, Hélio Francisco da ${ }^{2}$ \\ TASSO Júnior, Luiz Carlos ${ }^{3}$ \\ MARQUES, Diogo ${ }^{3}$ \\ MARQUES, Marcos Omir ${ }^{4}$
}

\begin{abstract}
RESUMO: Este trabalho teve como objetivo determinar e comparar os teores de acidez fixa, total e volátil para seis cultivares tardios de cana-de-açúcar, ao longo da safra 2008/2009. O experimento foi instalado no Município de Jaboticabal, São Paulo. O delineamento experimental utilizado foi o inteiramente casualizado em parcelas subdivididas, com 3 repetições. Os tratamentos principais foram os seis cultivares de cana com ciclo de maturação no meio de safra (IAC94-2101, RB72454, RB867515, CTC 2, CTC 6 e CTC 8) e o secundário as 5 épocas de análise $(0,14,28,42$ e 56 dias após a primeira análise). Em cada parcela foram coletados 3 feixes de cana, cada um contendo 10 colmos que foram encaminhados ao Laboratório de Tecnologia de Açúcar e Etanol da FCAV/UNESP para determinação da acidez total e volátil, os quais permitiram o cálculo da acidez fixa. Os resultados obtidos foram submetidos à análise de variância pelo Teste $\mathrm{F}$ e as médias foram comparadas pelo Teste de Tukey a $5 \%$ de probabilidade. Para a acidez fixa e total os cultivares apresentaram comportamento semelhantes ao longo da safra, sendo obtido os maiores teores ao final das épocas de análise. Para a acidez volátil, os cultivares obtiveram comportamentos distintos ao longo da safra. O resultado menos satisfatório foi obtido pelo cultivar IAC94-2101. Podemos concluir que os maiores valores de acidez fixa e total coincidiram com a época de maturação dos cultivares. Recomenda-se uma maior atenção com o cultivar IAC942101 e seus elevados teores de acidez.
\end{abstract}

Palavras-chave: Acidez. Saccharum spp. Variedades.

\section{ACIDITY LEVELS IN JUICE OF THREE LATE SUGARCANE VARIETIES}

SUMMARY: This work had the objective to determine and compare the fixed, total and volatile acidity levels for six late sugarcane varieties along 2008/2009 harvest. The experiment was installed at Jaboticabal County, São Paulo state. The experimental design used was completely randomized with subdivided plots, with 3 replications. The main treatments were the six sugarcane varieties with middle harvest maturation (IAC942101, RB72454, RB867515, CTC 2, CTC 6 and CTC 8) and the secondary treatments were the 5 analysis epochs $(0,14,28,42$ and 56 days after the first analysis. In each plot were collected 3 cane beams, each containing 10 stalks that were sent to the Laboratory of Technology of Sugar and Ethanol at FCAV/UNESP for total and volatile acidity determination, which allowed the calculations for fixed acidity. The obtained results were submitted to variance analysis through $\mathrm{F}$ Test and the averages were compared through Tukey Test at 5\% probability. For fixed and total acidity the varieties showed similar behavior along the harvest, being obtained the highest levels at the end of the analysis epochs. For volatile acidity, the varieties obtained distinct behaviors along the harvest. The less satifactory result was obtained by the variety IAC94-2101. The conclusion is that the highest fixed and total acidity levels coincided with the varieties' maturation epoch. It is recommended more attention with variety IAC94-2101 and its high acidity levels.

Keywords: Acidity. Saccharum spp. Varieties.

\footnotetext{
${ }^{1}$ Engenheira Agrônoma. Mestranda- produção vegetal. Departamento de Tecnologia.Laboratório do Açúcar e Etanol. UNESP/FCAV, campus Jaboticabal

${ }^{2}$ Engenheiro Agrônomo. Doutorando em Agronomia - Produção Vegetal pela FCAV/UNESP-Jaboticabal.

${ }^{3}$ Departamento de Tecnologia.Laboratório do Açúcar e Etanol. UNESP/FCAV, campus Jaboticabal

${ }^{4}$ Livre-Docente. Professor Adjunto na FCAV/Unesp - Campus de Jaboticabal
} 


\section{INTRODUÇÃO}

A determinação da acidez presente no caldo de cana-de-açúcar nos permite avaliar a possibilidade da qualidade em que ele se encontra e, a partir daí, escolher o melhor manejo a ser empregado no processo industrial.

Uma eficiente produção de açúcar e etanol, com baixos custos e de elevada qualidade está relacionado a teores adequados de acidez. Quando se encontram elevados valores de acidez no caldo de cana inúmeros problemas poderão ocorrer, como a redução da qualidade do produto final (CAMPOS, 1999).

Ripoli e Ripoli, (2004) estima valores de acidez sulfúrica abaixo de 0,8 como padrões ideais de qualidade do caldo de cana-de-açúcar. Tais teores de acidez são dependentes, dentre outros fatores, das características intrínsecas de cada cultivar, além do solo e do clima em que a cultura está instalada. Segundo Pereira (2007), os teores de acidez total e fixa estão diretamente relacionados com a fertilidade do solo, sendo que os maiores teores de acidez são encontrados em solos mais férteis.

A acidez total é definida como a somatória da acidez volátil com a acidez fixa, sendo que a principal componente da acidez total é a acidez fixa. Na agroindústria sucroalcooleira essa é a forma mais comum de determinação da acidez, sendo expressa em grama de ácido sulfúrico por litro de caldo. A acidez fixa pode ser decorrente do ácido láctico ou quando sua origem for o ácido acético se estabelece a acidez volátil do caldo (ALCARDE et al., 2002).

No processo de destilação para produção de aguardente é normal que uma pequena quantidade de ácidos seja levada, principalmente os voláteis. (NOBREGA, 1994).

Tasso Júnior et al., (2009) relaciona o aumento dos níveis de acidez e dextrana no caldo de cana-de-açúcar ao tempo de armazenamento por contaminação por bactérias e microrganismos.

Este trabalho teve como objetivo determinar e comparar os teores de acidez fixa, total e volátil para seis cultivares tardios de cana-de-açúcar, ao longo da safra 2008/2009.

\section{MATERIAL E MÉTODO}

A área experimental foi instalada na Fazenda de Ensino e Pesquisa da FCAV/UNESP, campus de Jaboticabal, localizada no mesmo município, estado de São Paulo, Brasil, a uma altitude média de 575 metros do nível do mar, o clima é do tipo tropical com inverno seco, e classificado, de acordo com o Sistema Internacional de Classificação de Köppen, como Aw. A pluviometria média da área se caracteriza por uma concentração de chuvas no verão e seco no inverno. 
O solo utilizado no experimento foi um Latossolo Vermelho eutroférrico (LVef) textura muito argilosa A moderado, (Embrapa, 1999). A amostragem do solo para fins de caracterização química (0-25 e $25-50 \mathrm{~cm}$ de profundidade) foi feita antes da instalação do experimento (Tabela 1), conforme os protocolos analíticos descritos em Raij et al. (2001).

Tabela 1. Características químicas do solo da área experimental. Jaboticabal-SP, 2007/2008.

\begin{tabular}{|c|c|c|c|c|c|c|c|c|c|c|}
\hline & $\mathrm{pH}$ & $\begin{array}{c}\mathrm{P} \\
\text { (resina) }\end{array}$ & M.O. & $\mathrm{K}$ & $\mathrm{Ca}$ & $\mathrm{Mg}$ & $\mathrm{H}+\mathrm{Al}$ & SB & CTC & $\begin{array}{l}\mathrm{V} \\
\%\end{array}$ \\
\hline \multirow{2}{*}{ Amostras } & $\mathrm{CaCl}_{2}$ & $M g d m^{-}$ & $g d m^{-}$ & ---- & $-\cdots$ & $-\cdots$ & $\mathrm{mmol}_{c} d n$ & $-3--$ & - & --- \\
\hline & & 3 & 3 & & & & -- & & & \\
\hline $0-25$ & 5.3 & 56 & 19 & 3.8 & 37 & 16 & 31 & 56.8 & 87.8 & 65 \\
\hline $25-50$ & 5.3 & 26 & 15 & 3.5 & 28 & 12 & 25 & 43,5 & 68.5 & 64 \\
\hline
\end{tabular}

Fonte: Departamento de solos - FCAV/UNESP

O delineamento utilizado foi blocos inteiramente casualizado, em parcelas subdivididas com seis tratamentos principais que foram os cultivares de cana-de-açúcar com ciclo de maturação no meio da safra (IAC94-2101, RB72454, RB867515, CTC 2, CTC 6 e CTC 8) e o secundário as 5 épocas de análise (0,14, 28, 42 e 56 dias após a primeira análise), em que a época zero corresponde à primeira avaliação, quando a cana apresentava 13 meses e 20 dias após o plantio, realizado no dia 20 de março de 2007.e três repetições. Os resultados obtidos foram submetidos à análise de variância pelo teste $\mathrm{F}$, e as médias foram comparadas pelo teste de Tukey, a 5\% de probabilidade.

As parcelas experimentais foram compostas por 5 linhas de cana com 12 metros de comprimento, espaçadas de $1,5 \mathrm{~m}$, totalizando $90 \mathrm{~m}^{2}$, sendo considerada como área útil as 3 linhas centrais, descartando-se 1 metro nas extremidades, totalizando $45 \mathrm{~m}^{2}$. Em cada parcela foi coletado um feixe de cana contendo 10 colmos de cana retirados em sequência na linha de plantio. Os colmos foram despalhados, despontados e encaminhados para o Laboratório de Tecnologia do Açúcar e Etanol da FCAV/UNESP, campus de Jaboticabal. No caldo extraído dos colmos determinou-se a acidez total e volátil, e de posse destes resultados calculou-se a acidez fixa de acordo com Marques et al., (2008). Os resultados obtidos foram submetidos à análise de variância pelo teste $\mathrm{F}$, e as médias foram comparadas pelo teste de Tukey, a 5\% de probabilidade.

\section{RESULTADOS E DISCUSSÃO}

Os valores médios de acidez total, volátil e fixa coletadas em diferentes épocas, se encontram na Tabela 1. 
O cultivar IAC94-2101 obteve o maior valor de acidez total 1,02, considerado elevado por Ripoli e Ripoli (2004) que estima acima de 0,8 como padrões ideais de qualidade do caldo de cana-de-açúcar. É possível relacionar este alto valor de acidez a uma elevada taxa de isoporização do colmo (SILVA NETO et al., 2009) ou a uma maior taxa de dextrana (TASSO JÚNIOR et al., 2009). Em relação às épocas em estudo, os maiores valores foram obtidos no final da época analisada. Tais valores podem indicar perdas de qualidade do caldo ao longo do período analisado.

O caldo do cultivar CTC 2 apresentou maior teor de acidez volátil. Em relação à época analisada ocorreu um aumento no final do período em estudo, tais valores ressaltam a importância de analisar as frações de acidez no caldo de cana-de-açúcar durante a safra. Segundo relatos de Nóbrega (1994) no processo de aguardente de cana-de-açúcar é normal levar uma pequena quantidade de ácidos voláteis, mas se obtidos nas épocas iniciais podem diminuir a qualidade das aguardentes (CAMPOS, 1999). É importante ressaltar a destinação do caldo de cana-de-açúcar, pois para a produção de aguardente a época final para a colheita seria mais favorável.

Os valores médios da acidez fixa mostraram os mesmos da acidez total. Tal fato é explicado devido à acidez fixa ser representada pela acidez total (ALCARDE, 2002).

Tabela 1: Valores médios de acidez total, acidez volátil e acidez fixa, obtida pelos seis cultivares de cana-de-açúcar nas diferentes épocas analisadas ao longo da safra 2007/2008

(Continua)

\begin{tabular}{lccc}
\hline Tratamentos & Acidez Total & Acidez Volátil & Acidez Fixa \\
\hline Cultivares Tardios (C) & $\mathrm{g} \mathrm{H}_{2} \mathrm{SO}_{4} \mathrm{~L}^{-1}$ & $\mathrm{~g} \mathrm{C}_{2} \mathrm{H}_{4} \mathrm{O}_{2} \mathrm{~L}^{-1}$ & $\mathrm{~g} \mathrm{C}_{3} \mathrm{H}_{6} \mathrm{O}_{3} \mathrm{~L}^{-1}$ \\
\hline CTC 2 & $0,44 \mathrm{e}$ & $0,022 \mathrm{a}$ & $0,74 \mathrm{e}$ \\
CTC 6 & $0,59 \mathrm{c}$ & $0,018 \mathrm{bc}$ & $1,03 \mathrm{c}$ \\
CTC 8 & $0,73 \mathrm{~b}$ & $0,016 \mathrm{bc}$ & $1,29 \mathrm{~b}$ \\
IAC 94-2101 & $1,02 \mathrm{a}$ & $0,021 \mathrm{ab}$ & $1,82 \mathrm{a}$ \\
RB 72454 & $0,57 \mathrm{c}$ & $0,015 \mathrm{c}$ & $1,007 \mathrm{c}$ \\
RB 867515 & $0,49 \mathrm{~d}$ & $0,019 \mathrm{abc}$ & $0,85 \mathrm{~d}$ \\
\hline Teste F & $422,74^{* *}$ & $8,34 * *$ & $428,89 * *$ \\
DMS (5 \%) & 0,048 & 0,004 & 0,089 \\
\hline Época (dias) & & $0,01 \mathrm{bc}$ & $0,85 \mathrm{c}$ \\
\hline 0 & $0,48 \mathrm{c}$ & $0,02 \mathrm{~b}$ & $0,85 \mathrm{c}$ \\
14 & $0,49 \mathrm{c}$ & $0,01 \mathrm{c}$ & $0,74 \mathrm{~d}$
\end{tabular}


Tabela 1: Valores médios de acidez total, acidez volátil e acidez fixa, obtida pelos seis cultivares de cana-de-açúcar nas diferentes épocas analisadas ao longo da safra 2007/2008

(Conclusão)

\begin{tabular}{llll}
42 & $0,64 \mathrm{~b}$ & $0,01 \mathrm{c}$ & $1,12 \mathrm{~b}$ \\
56 & $1,15^{\mathrm{a}}$ & $0,02^{\mathrm{a}}$ & $2,05 \mathrm{a}$ \\
\hline Teste F & $890,47^{* *}$ & $29,61^{* *}$ & $883,27^{* *}$ \\
DMS $(5 \%)$ & 0,039 & 0,003 & 0,072 \\
\hline F para Interação & & & \\
\hline CxE & $109,31^{* *}$ & $11,25^{* *}$ & $883,27^{* *}$ \\
CV\% parcela & 6,21 & 19,08 & 6,45 \\
CV\% subparcela & 6,59 & 17,37 & 6,83
\end{tabular}

1-Números seguidos de letras distintas diferem entre si a $5 \%$ de probabilidade, pelo Teste de Tukey. ${ }^{\text {NS }} \mathrm{e}^{* *}$ Não Significativo e significativo ao nível de $1 \%$ de probabilidade, pelo teste F, respectivamente. DMS Diferença mínima significativa. CV \% - Coeficiente de variação.

O desdobramento dos cultivares dentro das épocas analisadas, em relação à acidez total, volátil e fixa, estão representados nas Figuras 1,2 e 3, respectivamente.

O cultivar CTC 2 se destacou por apresentar o menor teor de acidez total durante o período analisado. Os demais cultivares apresentam elevados valores de acidez total no final da época analisada, que podem atribuir redução da sacarose e menor qualidade da matéria prima (AMORIM, 2005).

A variação dos valores da acidez volátil ao longo do tempo, para os diferentes cultivares apresentaram oscilações, embora estivessem muito próximos. Contudo, o cultivar CTC 2 obteve valores mais elevados que se destacaram dos demais. Esse comportamento diferenciado permite a inferência de que há grande probabilidade de que a variáveis estudadas para esse cultivar demonstram ser o mesmo potencialmente inferior aos demais, o que pode refletir no produto final como destaca (CAMPOS, 1999).

Os cultivares CTC 2, RB72454 e RB867515 apresentaram comportamentos semelhantes durante o período analisado, para acidez fixa, estável até os 42 dias, passando a aumentar a partir desse ponto. O cultivar IAC94-2101 se mostrou estável até os 28 dias, sendo que a partir desse momento obteve o maior valor. Tais resultados podem ser explicados pela maior contaminação do caldo por bactérias, que resulta da maior susceptibilidade da planta. Tasso Júnior et al. (2009), assim como neste estudo, também relacionou o aumento de acidez e dextrana a uma maior contaminação do caldo provocado pelo tempo de armazenamento dos colmos de cana. 


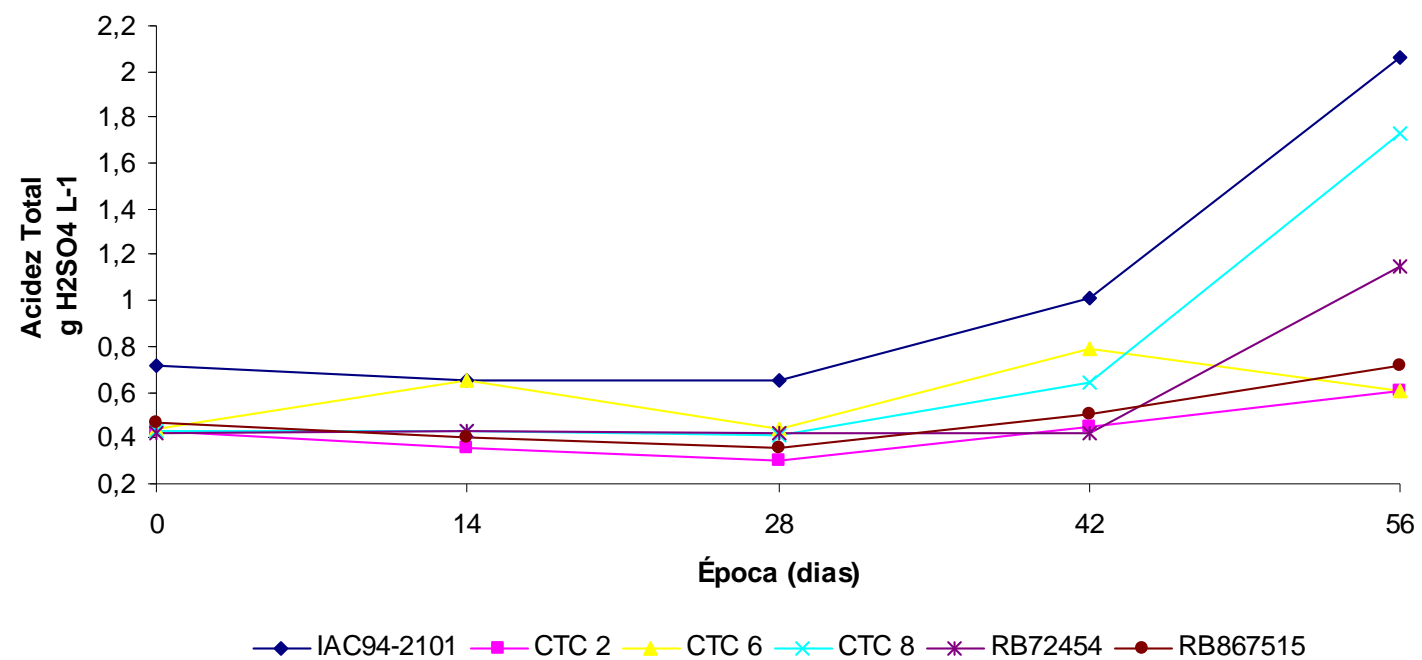

Figura1: Desdobramento dos cultivares analisados e épocas de estudo sobre a acidez total na safra 2008/2009.

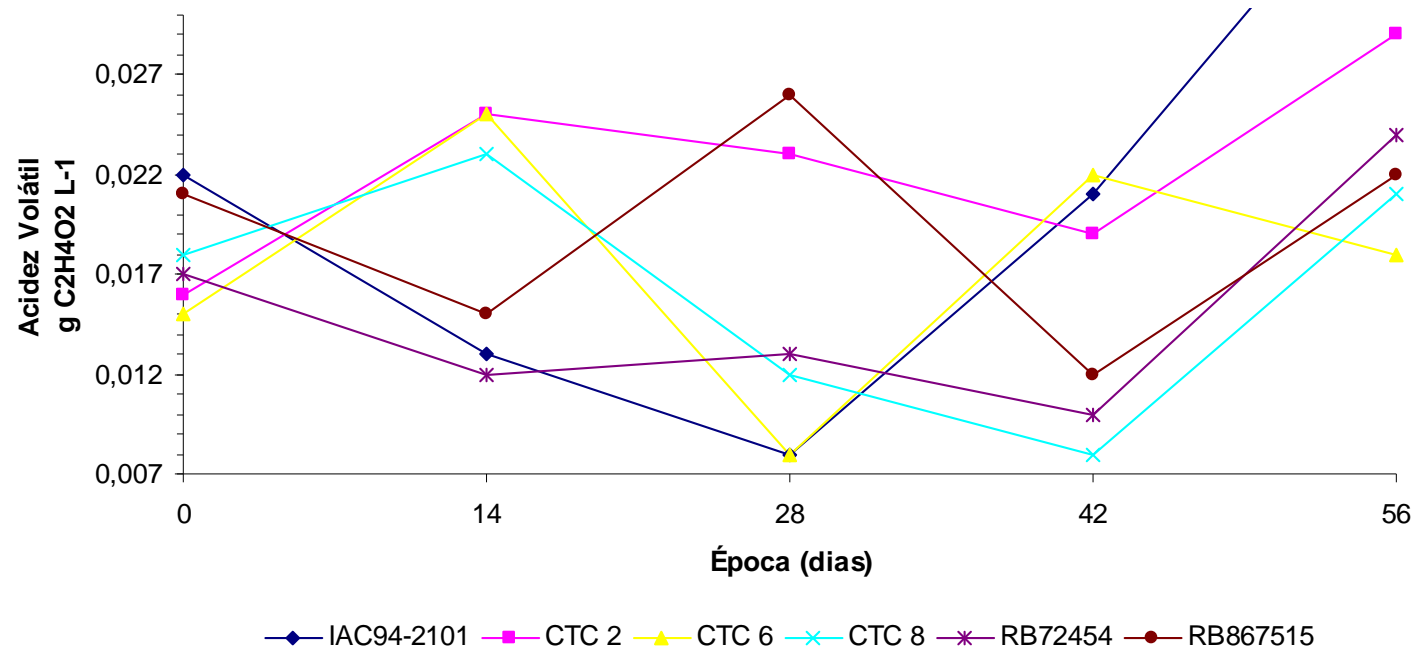

Figura2: Desdobramento dos cultivares analisados e épocas de estudo sobre a acidez volátil na safra 2008/2009.

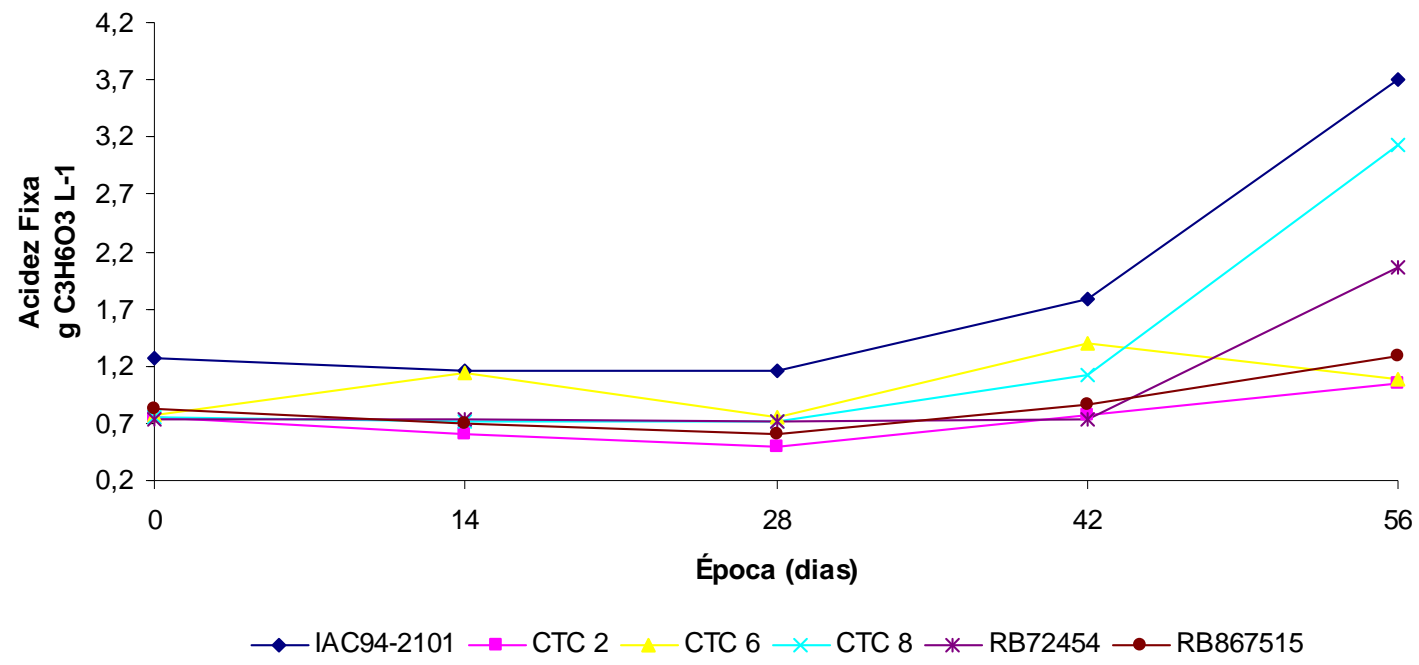

Figura 3: Desdobramento dos cultivares analisados e épocas de estudo sobre a acidez fixa na safra 2008/2009. 


\section{CONCLUSÃO}

Pode-se concluir que os maiores valores de acidez fixa e total coincidiram com a época de maturação dos cultivares. Recomenda-se uma maior atenção com o cultivar IAC942101 e seus elevados teores de acidez.

O cultivar CTC 6 apresentou os menores valores de acidez durante a época analisada, possibilitando sua colheita em época final de safra.

\section{REFERÊNCIAS}

AMORIM, H. V. Fermentação alcoólica: ciência; tecnologia. Piracicaba: Fermentec, 2005, 448 p: il.

ALCARDE, A. R. et al. Effect of radiation on physiological parameters of the ethanolic fermentation. World journal of microbiology ; biotechnology, Netherlands, v 18, p. 41-47, 2002.

CAMPOS, G. A, et. al. Cachaça: qualidade e produção. 1999. p. 07-14, Dissertação (Mestrado) Universidade Federal de Lavras .

EMBRAPA - Empresa Brasileira de Pesquisa Agropecuária. Centro Nacional de Pesquisa de Solos 1999. Sistema brasileiro de classificação de solos. Brasília: Embrapa. Produção de informação, Embrapa solos, 1999, 412p.

MARQUES, M.O. et al. Considerações sobre a qualidade da matéria-prima. In: MARQUES M.O. et al. Tecnologias na agroindústria canavieira. Jaboticabal: FCAV, 2008. p.9-16.

NÓBREGA, I.C.C. Características de qualidade de aguardentes de cana comerciais e comparação entre dois processos de fermentação. 1994. 67 p. Dissertação (Mestrado) Departamento de Tecnologia de Alimentos, Universidade Federal de Viçosa.

PEREIRA, C.B. Acidez do caldo na caracterização de cultivares de cana-de-açúcar. 2007, 53p. Faculdade de Ciências Agrárias e Veterinárias, Universidade Estadual Paulista, Jaboticabal.

RAIJ, B. van; QUAGGIO, J.A. Determinação de fósforo, cálcio, magnésio e potássio extraídos com resina trocadora de íons. In: RAIJ B. van et al. Análise química para avaliação da fertilidade de solos tropicais. Campinas: Instituto Agronômico, 2001. p.189199.

RIPOLI, T. C. C.; RIPOLI, M. L. C. Biomassa de cana-de-açúcar: colheita, energia e ambiente. Piracicaba: Barros ; Marques Ed. Eletrônica, 2004. 302 p.

SILVA NETO, H. F.et al. Algunas características agrotecnológicas de la caña de azúcar. In: Tecnicaña - CONGRESO DE LA ASSOCIACIÓN COLOMBIANA DE TÉCNICOS DE LA CAÑA DE AZÚCAR, 8, Memórias..., p. 58-64, 2009. 
TASSO JÚNIOR, L. C.et al Calidad química em el almacenamiento de la caña de azúcar. In: Tecnicaña - CONGRESO DE LA ASSOCIACIÓN COLOMBIANA DE TÉCNICOS DE LA CAÑA DE AZÚCAR, 8, Memórias..., p. 771-779, 2009. 